\title{
Advertise with Social Discourse, as a Brand Positioning Technique: Review of Research with Special Reference to the Latvian Media
}

\author{
Aivars Gabriel Helde \\ Department of Communication, Riga International School of Economics and Business Administration (RISEBA), Latvia
}

Copyright (C) 2015 Horizon Research Publishing All rights reserved.

\begin{abstract}
This study examines the nature of the social discourse of advertising used as a brand positioning discourse. The focus is on consumer advertising, which is directed towards the promotion of some product or service to the general public. The study, however, is not meant to exhaust all the aspects of this particular discourse, or present an answer to all the problems it poses. This paper aimed at analyzing some different commercial advertisements (product/non-product ads) to investigate the intentions and techniques of consumer product companies to reach more consumers and sell more products. Norman Fairclough's 3-D model and Kress and van Leeuwen's grammar of visual design were used to analyze the data for professionals, but we are pointed on using stereotypes. Traditionally, stereotypes are defined as patterns or schemes via which people organize their behaviors and activities. Psychologists have been extremely interested in the persuasion techniques used by advertisers. The implicate question that most of such studies have entertained is whether advertising has become a force molding cultural mores and individual behaviors, or whether it constitutes no more than a "mirror" of deeper cultural tendencies within urbanized contemporary society. The one thing which everyone agrees is that advertising has become one of the most recognizable and appealing forms of social communication to which everyone in society is exposed. However, it could be understood from the results that the producers, generally tend to use their power and ideology to change people's behaviour and thought. Sometime more efficiently is used "old" stereotypes and do not try to going to change people's behaviuor but do conversely use their power to preserve previous behaviour try to reinforces this behaviour, shown this like some traditional value what confirmed customers identity. When we consider gender stereotypes we look at notions about the supposedly traditional behaviours of men and women and the characteristics and standards of these behaviours, as grounded in our culture and society. This idea allows to producers make customer feel belonging to this society and psychologically be involved into story what is shown by advertisers. Culture covers human values, action patterns,
\end{abstract}

ideas, and material and artificial surrounding which enable interaction among people. The content of culture determines the particular qualities of certain groups of people, and it also determines their consumer characteristics. That is why it is essential to understand the way in which culture reaches individuals. In today's information area, the media are the primary means for the transmission and reproduction of cultural information. They shape the image of culture in people's consciousness. In addition this study provides analyses of some ads, using different ways of interpretations. All materials are taken from Latvian media.

Keywords Social Discourse Analysis, Stereotypes Brand, Customer Behaviour, Print Advertisement, Image, Fairclough-3D, Krees and Van Leeuwen's Grammar, Gestalt Psychology, Culture

\section{Introduction}

As the elements of the marketing program come together to create the complete offering, marketers must also consider how the marketing program will be used to create effective branding and positioning.

While the concept of a brand may seem relatively simple to understand, branding strategy can actually be quite complex. From a technical point of view, a brand is a combination of name, symbol, term, or design that identifies a specific product. Brand have two parts: the brand name and the brand mark.( O.C. Ferrell.,M.D. Hartline 2014).[1]

The brand name is the part of a brand that can be spoken, including words, letters and numbers.( Laima, KDF, 7-up).The brand mark- which include symbols, figures, or a design -is the part of brand that cannot be spoken.( Nike's swoosh). Jenni Romaniuk, professor from Ehrenberg-Bass Institute says: "Distinctive assets are the branding elements that uniquely identify the brand across the vast majority of category buyers, such as the Nike Swoosh or red and yellow M\&Ms. The opportunity and challenge of distinctive assets is that potential assets can come from a wide source of 
possibilities, from colours, fonts, advertising style, celebrities, characters or logos - just to name a few."

While these technical aspects of branding are important, branding strategy involves much more than developing a clever brand name or unique brand mark. Good brands are those that immediately come to mind when a customer has a problem to be solved or a need to be fulfilled. So it is "the battle for your mind" (A. Rise., J. Trout., 2009).[2]

However, for most people advertising is something to encourage or persuade them to buy a special product. But advertisings do not only serve this purpose, they "also amuse, inform, misinform, worry, though it may be argued that these function are all in the service of the main function" (Cook 1992).[3] Considering the other side, there are non-product advertisements as well that without promoting any products only advocate a change in behavior. The non-product ads are used in different campaigns and they show the effects of not adopting the advocated behavior. "Ads may not always be obliged to refer to a product, but they are still obliged to refer, however obliquely, to a change of behavior"'(Cook,1992).[3]

Our days is very modern to use the third possibility -to combine both this techniques and promote product using different cultural and behavioral stereotypes. The aim of this advertises is not to change some one habits of behaviour but on the contrary-seek to maintain or strengthen this habits.

Advertisings have been involved with our everyday lives: it's mirroring of society and it's transmitting of meaning and message, and it's social significance have lead people to consider it as a discourse type. Cook (1992) also remarks that "advertising is not a remote and specialized discourse, but a prominent discourse type in contemporary society."

Discourse has been described by Gee (2005) as "language (oral or written) in use with more socio-politically oriented meaning." Fairclough (1989) goes further and defines it as "just a particular form of social practice" that in its center power and ideology influence and interact with one another.. In other words, discourse constitutes social practice and is at the same time constituted by it (Wodak, 1999).[4]

Intertextuality has been described as texts [which] are recognized in terms of their dependence on other relevant texts. Essentially it amounts to the relationship between text and the various language or signifying practices of a culture and its relation to those texts which articulate for it the possibilities of that culture. Therefore, one reason for the success of an advertisement or commercial may well be the underlying relationship between its presentation and a literary association familiar to the target audience.

"Standard ad messaging and conventional creative executions and placement re rapidly becoming out-moded. To win consumer's attention and trust, marketers must think less about what advertising says to its targets and more about what it does for tem" J.F. Rayport ( Business Harvard review.2013.March)[5]

\section{Statement of the Problem and Purpose}

Many studies of advertising do separate out components of ads, concentrate on one or a few and ignore the others. There are some theories traditionally used as Fairclough-3D, Krees and van Leeuwen's visual grammer, very good for students and researchers but not useable for customers.

The successful ads are described in their three basic parameters. Strategy, creativity, fabrication. The strategy: Specific target selection, the target audience's choice, report creation and media planning. Very understandable and clear. Describing advertising as discourse is both more complex and more difficult than any of these approaches. It must be borne in mind, then, that there is a danger of dilution in analysis which attempts to tackle too much.

Professionals advise marketers to approach this medium as a landscape composed of four domains: the public sphere, where we move from one place or activity to other, both online and off; the social sphere, where we interact with and relate to one another; the tribal sphere, where web ffiliate with groups to define or express our identity; and the psychological sphere, where we connect language with specific thoughts and feelings.( Rayport, Jeffrey F. and Jaworski, Bernard J. (2004)Best Face Forward, Why Companies Must Improve Their Service Interfaces with Customers. Harvard Business School Press, January 2005).[6]

We will try to focus on local - Latvian ads with social discourse as principle of a brand communication with customer, based on customer cultural habits and expectations.

\section{Social Responsibility and Advertising}

The traditional view of marketing holds that ethics and social responsibility are good supplements to business activities but may not be essential. Today we can see that ethical behavior can not only enhance a company's reputation, but also contribute significantly to its bottom line.(I Maignan.,T.L. Gonzales-Padron,G. Tomas, M. Hult, and O.C.Ferrell- cloudapps-http://www.cloudapps.com/sele sforce-carbon-reporting,accessed May 29,2012) and I. Nooyi "the responsible company", The economist, March 31,2008 .)[7]

"Social responsibility is a broad concept that relates to an organization's obligations to maximize its positive impact on society while minimizing its negative impact. Social responsibility consists of four demensions : economic, legal, ethical and philanthropic "( A.Carroll," The pyramid of corporate social responsibility: Toward the moral management of organizational stakeholders", Business Horizons,34-1991).[8]

If company try to ignoring a social responsibility -it can destroy customers trust to company. In response to customers' demands, along with the threat of increased regulations, firms increasingly incorporate ethics and social responsibility into the strategic marketing plan.

By other way firms pretend to be social responsible but 
really in the way how it turns out this is just a marketing trick. As says de Bono, [9] it is not easy to realize where is the line between social responsibility and pretending to be socially responsible.

Accordingly, ads can be explained using a meaningful discourse. One of the method could be Hall's(1973)- The theory of encoding/decoding.

The term encoding describes the process of the production of the message, while decoding is about the reception and how the receiver makes sense out of the encoded message. Hall says: In the advertising discourse, for example, we might say that there is almost no "purely denotative" communication. Every visual sign in advertising "connotes" a quality, situation, value or inference which is present as an implication or implied meaning, depending on the connotational reference. (Stuart Hall,1973 http://people.ucalgary.ca/ rseiler/hall.htm).[10]

This theory could be used to analyze the type of discourse to clearly realised the implicit ideologies what is behind this ads.

For better analyze images as researchers we can use method described by Fairclough(1995) and later developed by Kress and van Leeuwen(1996) well known as "Visual grammer"[11]

"We take the view that language and visual communication both realize the same more fundamental and far- reaching systems of meaning that constitute our cultures, but that each does so by means of its own specific forms, and independently"( Kress and van Leeuwen, 1996).

Fairclough [12] developed three-dimensional boxes. The inner box presents the text, the middle box - the discourse practice, and the outer one presents the socio- cultural practice .In printed advertisement these two made multimodal message.

Kress and van Leewen define two components for visual discourse: represented participants and interactive participants. By represented participants they mean people or things that are mapped on an image, while by interactive participants they mean producers and viewers. Among all these participants exists relations. The relations between the represented participants can be considered as syntactic, between the represented and interactive participants as sematic and between interactive participants as pragmatic.

However, even though people mindlessly absorb the messages promulgated constantly by advertisements, and although these may have some subliminal effects on behavior, we accept media images, by and large, only if they suit our already established preferences. It is more accurate to say that advertising produces images that reinforce lifestyle models. Advertisers are not innovators. They are more intent on reinforcing lifestyle behaviors than in spreading commercially risky innovations. In this sense, advertisements are not in themselves disruptive of the value systems of the cultural mainstream; rather, they reflect shifts already present in popular culture. And if they are really psychologically effective, it is primarily because they tap into deep-ingrained mythical and metaphorical structures of the mind (Johnson-Laired, 2004; Mothersbaugh et $\mathrm{al} /, 2002)[13]$

\section{4. "Schemas" and Commercial Advertising with Social Discourse}

It is no exaggeration to claim that today most of our information, intellectual stimulation, and lifestyle models come from, or are related to, advertising images. This is an era in which advertising messages have moved away from describing the product in itself to focusing on the consumer of the product, creating product imagery with which the consumer can easy identify. Today we can say that ads and commercials now offer the same kinds of promise and hope to which religions and social philosophies once held exclusive rights: security against the hazards of old age, better positions in life, popularity and personal prestige, social advancement, better health, and happiness. Marketers are pushing advertising's boundaries. Different companies have fueled the growth of so-called native content, creating both text and video that complement commercial messaging and encourage consumers to engage with it because it's more than an advertisement. Such advertising is conspicuously different from the conventional sort. In the best cases, it has editorial integrity and engages through relevance and value. But not matter how worthwhile your message, competing for attention simply by shouting louder across the proliferating array of media platforms is not sustainable strategy." If human experience is a medium for advertising, how can marketers engage consumers there in way they will welcome? ( J. R. Rayport,2013). Rather than focusing first on communication strategy and marketing mix, they should begin by considering how consumers live their lives and under what circumstances they will prove receptive to messages in this domains.[14]

For analyzing different advertisements had been selected as product ads and non-product ads. Since the aim of the study was to pull back the "ideological curtain" to see the power and ideology behind images,[15]the chosen ads have more visual and less text. In other words, they communicate through images and pictures.

These advertisements are from Latvian media and brand promotion through social discourse.

Dimension of discourse and discourse analysis [16] can be described in next positions:
1. Text description
a)representing
b)relating
c)identifying

this is positions for text analysis

2. Discursive practices (analysis/interpretation -position for processing

\section{Social practices- social analysis/explanation}

So we can call for the first dimension text analysis or description, for the second dimension processing analysis or interpretation, for the third dimension it is the social analysis or explanation. All dimensions are interdependent and 
therefore it does not matter with which kind of analysis one starts.

\section{Materials}

Four different advertisements, product ads and non-product ads, had been selected for analyizing. Since the aim of the study was to pull back the "ideological curtain" to see the power and ideology behind images,[17] the chosen ads have more visuals and less text. The chosen advertisements communicate through images and pictures. Thee advertisements are: "For a real childhood"(see postern.1),"Help put Your baby in the world"(see postern.2), "It makes no sense to live longer"(see postern3), "Motociclist's summer"(see postern4).

1. Sweets manufacturer, company "Laima" Here we have a picture of a baby in hammock.

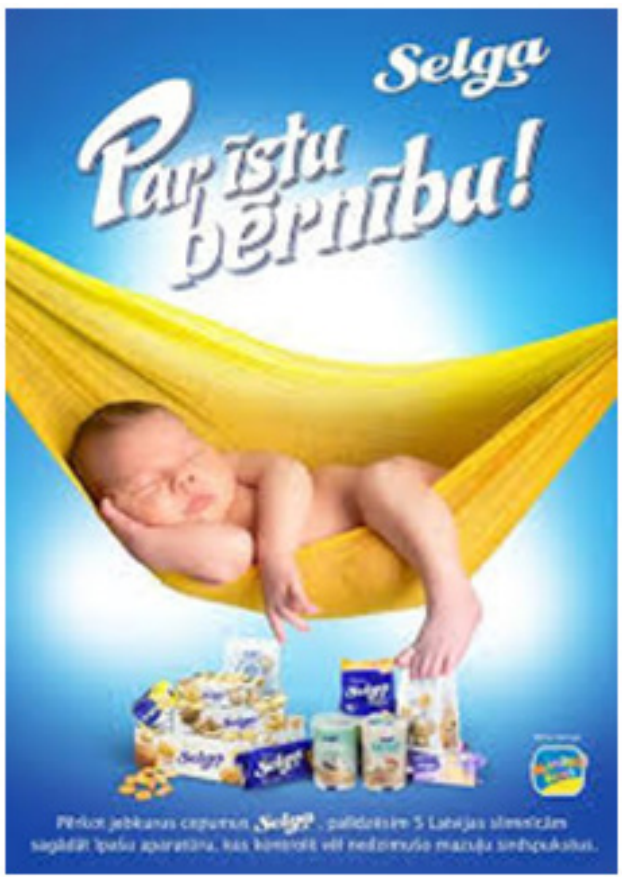

Figure 1. Poster "For a real Childhood"

The colors used in this ad are blue, white and yellow. The color blue gives peace to the viewer but color yellow gives contrast but color white behind the picture of baby attract the viewers' attention and invite her/him to bay biscuits what lie below Picture with baby. Above Picture of baby is written in white:" For a real childehood, Selga". Company "Laima" is the producer of this product( biscuit)ad and aims to show company as social responsible one, who care about children. The discourse of this "Laima" product could be considered as charity. Therefore, the viewer has the power to choose the biscuits or not. There is no force.

2. Firm "Elvi"(the store chain ) made camaing-"Help put Your baby in the world".

This is Picture of happy family. Mother, Father and baby. The company "Elvis" is the producer of this ad, there no text because this is picture from booklet. The colors in this advertising is light, accent is on baby-pale bluish-green towel, man kissing woman and she kissing baby. The viewer is nearly too intimate with the family. On the booklet below is written:" Help put your baby in the world". This ad is considered to charity and tries to solving a problem. As a result, the viewer has a power to be involved or not. This is no power above to force her/him.

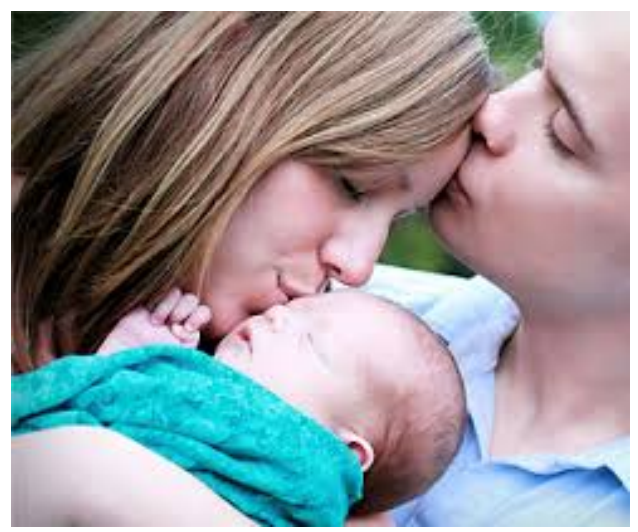

Figure 2. Poster Help put your baby in the world"

3. TV channel-3 realized campaign "It makes no sense to live longer" about abandoned pets.

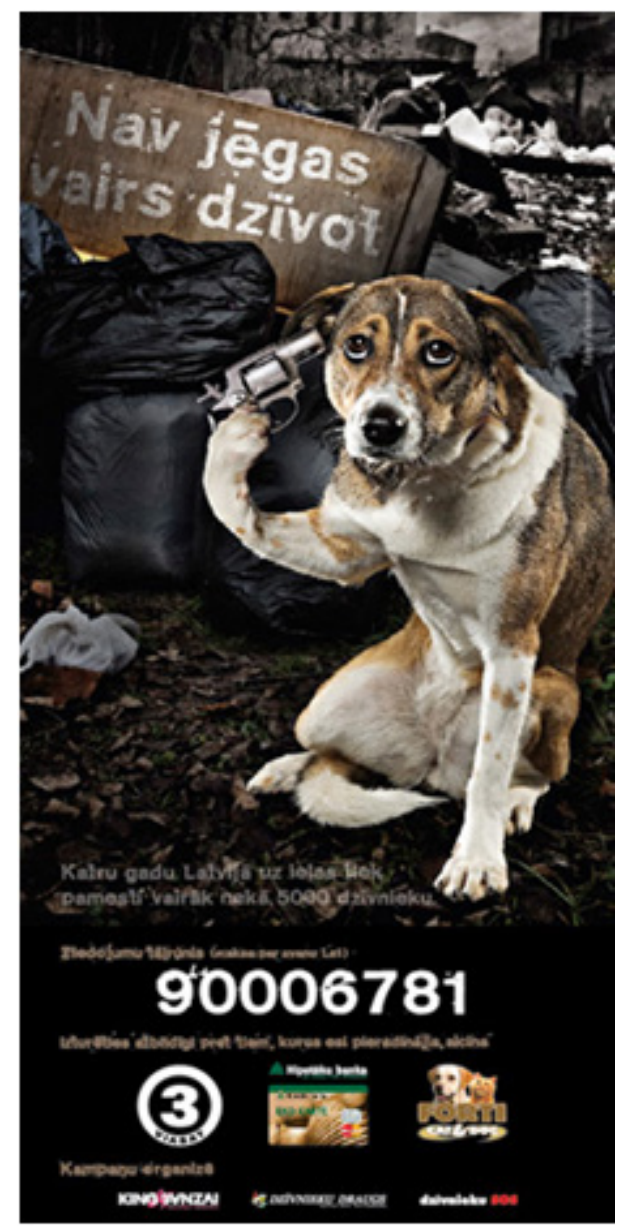

Figure 3. Poster "It makes no sense to live longer" 
This is non-product ad. As a result, its discourse is social responsibility-to highlight the social problem. The colors in this advertisement are dark and gloomy, only picture of a dog is more or less bright and the producer of this advertisement is TV channel-3.In the picture a dog with gun on his head, behind on a box is written "It makes no sense to live longer". This ad is aiming to pay attention at problem. The eye level angel shows the power balance on the side of viewer. The viewer can feel the tragically results of not helping to pets. As a result, the viewer should obey the advertisement.

4. Firm "Aldaris"(Beverage manufacturer), comparing "How Latvians love beer".

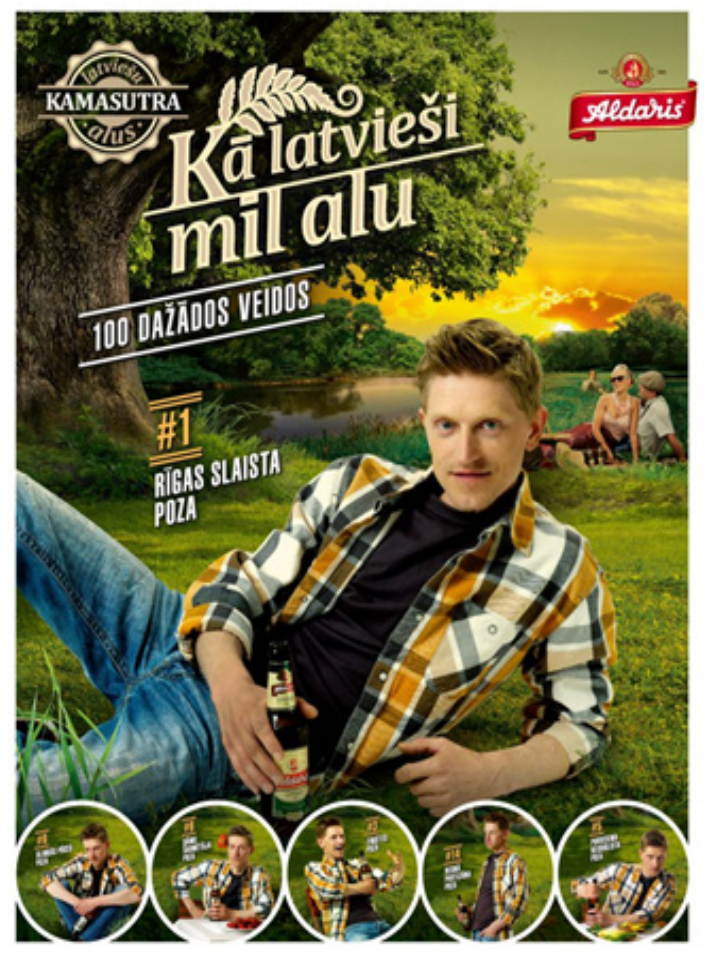

\section{alkohola lietošanal IR negatĩna IETEKmE}

Figure 4. Poster Motociclist summer

Here we have a picture of a young man behind him, we can see a young couple. A Young man is greens with bottle of beer into his hands. The colors used in this ad are light and pleasant; these bright colors attract the viewer's attention and encourage her/him to read the ad. This ad gives romantic sense to the viewer. On the corner of top of Picture is company's logo, in red and white color, on top of picture, above young man image, is written: "Latvian beer kamasutra. How latvians love a beer in 100 different positions.No1 runabout of Riga". The discourse of this ad considered as lifestyle discourse, because it is reminder of tradition. Therefore, the viewer has the power to choose the beer or not, there is no force.

\section{Conclusions}

The purpose of this study was to analyze some advertisement, product ads and non- product ads in order to see when the producer use their power to imply something to viewer. The analysis showed us, that today it is very modern to use social discourse for commercial ads. This technique allowed producers to make better relation between viewers (consumers) and company. In this case we use power in discourse as a form of social practice in various ways. Power behind discourse describes the formation of the order of social practices, which are themselves shaped and constituted by power relation. By analyzing these advertisements and defining the position of the viewers the followings were concluded: -the producers try to show that the viewer has the power to choose or not to choose something

The ideology behind the images[18] could be that powerful person should show her/his power; therefore, the powerless persons obey her/him. As a whole, it could be seen that producers use their power and ideology to change the behavior and thought of people. In case, if people are aware of this fact they can be more submissive, because they can imagine themselves in offered situations. This work as better as the narrative of situation is recognizable.

So, we can say, that the socio-historical conditions that govern these processes of production and reception is containing. Interpretations of this power will be as effective as accurately we speak to the viewer.

\section{REFERENCES}

[1] Ferrell.O.C.;M.D.Hartline-"Marketing Strategy Text and Cases" South-Western Cengage Learning,2013

[2] Al Ries.,Jack Trout - "Positioning: the battle for Your mind"Mc Graw-Hill,2001.

[3] Cook,.G the discurse of advertising. London and NY: Routledge, 1992

[4] Wodak R. -“Gender and discourse” Sage Publications, 1997

[5] J.F. Rayport( Business Harvard review.2013.March)[5]

[6] Rayport, Jeffrey F. and Jaworski, Bernard J. (2004) Best Face Forward, Why Companies Must Improve Their Service Interfaces with Customers. Harvard Business School Press, January 2005.

[7] IMaignan.,T.L.Gonzales-Padron,G.Tomas, M.Hult, and O.C.Ferrell-

cloudapps-http://www.cloudapps.com/selesforce-carbon-rep orting,accessed May 29,2012) and I. Nooyi "the responsible company"," The economist, March 31,2008.)

[8] Carroll," The pyramid of corporate social responsibility: Toward the moral management of organizational stakeholders", Business Horizons,34-1991).

[9] Six Thinking Hats by Edward de Bono,1989

[10] Stuart Hall,1973 - http://people.ucalgary.ca/ rseiler/hall.htm, Hall, Stuart. Encoding /Decoding, in Culture, Media, 
Language. London, Hutchinson 1980

[11] http://newlearningonline.com/literacies/chapter-9/kress-andvan-leeuwen-on-images-and-writing

[12] www.uv.es/gimenez/Recursos/criticaldiscourse.pdf

[13] (Johnson-Laired,2004;Mothersbaugh et al/,2002)

[14] https://hbr.org/2013/03/advertisings-new-medium-human-ex perience

[15] http://www.academia.edu/2645766/Critical_Discourse_Anal ysis_and_Faircloughs_Model-_Mirzaee_and__Hamidi_2012_
[16] Kress G.,and Van Leeuwen T.Reding images-Victoria, Deakin University Press ,1990

[17] Kelly, Aidan, Katrina Lawlor, and Stephanie O'Donohoe. "Chapter 8- Encoding Advertisements: The Creative Perspective." The Advertising and Consumer Culture Reader. By Joseph Turow and Matthew P. McAllister. New York: Routledge, 2009

[18] Teun A. Van Dijk-“Discourse and manipulation", Discourse and society Sage, 2006.,

http://www.uv.es/gimenez/Recursos/criticaldiscourse.pdf 